\title{
(2) OPEN ACCESS \\ Costs of postoperative morbidity following paediatric cardiac surgery: observational study
}

\author{
Emma Hudson 이, ${ }^{1}$ Katherine Brown, ${ }^{2}$ Christina Pagel 이, ${ }^{3,4}$ Jo Wray, ${ }^{2}$ David Barron, ${ }^{5}$ \\ Warren Rodrigues, ${ }^{6}$ Serban Stoica, ${ }_{1}^{7}$ Shane M Tibby (1) , ${ }^{8}$ Victor Tsang, ${ }^{2}$ \\ Deborah Ridout, ${ }^{9}$ Stephen Morris ${ }^{1}$
}

- Additional material is published online only. To view please visit the journal online (http://dx.doi.org/10.1136/ archdischild-2019-318499)

For numbered affiliations see end of article.

Correspondence to Emma Hudson, Department of Public Health and Primary Care, University of Cambridge, Cambridge CB2 1TN, UK; eh645@medschl.cam.ac.uk

Received 8 November 2019 Revised 27 February 2020 Accepted 11 April 2020 Published Online First 7 May 2020
Check for updates

(C) Author(s) (or their employer(s)) 2020. Re-use permitted under CC BY-NC. No commercial re-use. See rights and permissions. Published by BMJ.

To cite: Hudson $\mathrm{E}$, Brown $\mathrm{K}$, Pagel C, et al. Arch Dis Child 2020;105:1068-1074.

\begin{abstract}
Objective Early mortality rates for paediatric cardiac surgery have fallen due to advancements in care. Alternative indicators of care quality are needed. Postoperative morbidities are of particular interest. However, while health impacts have been reported,

\section{What is already known on this topic?}

- There is no evidence which accurately describes the cost of early morbidities following paediatric cardiac surgery.
\end{abstract} associated costs are unknown. Our objective was to calculate the costs of postoperative morbidities following paediatric cardiac surgery.

Design Two methods of data collection were integrated into the main study: (1) case-matched cohort study of children with and without predetermined morbidities; (2) incidence rates of morbidity, measured prospectively. Setting Five specialist paediatric cardiac surgery centres, accounting for half of UK patients.

Patients Cohort study included 666 children (340 with morbidities). Incidence rates were measured in 3090 consecutive procedures.

Methods Risk-adjusted regression modelling to determine marginal effects of morbidities on perpatient costs. Calculation of costs for hospital providers according to incidence rates. Extrapolation using mandatory audit data to report annual financial burden for the health service.

Outcome measures Impact of postoperative morbidities on per-patient costs, hospital costs and UK health service costs.

Results Seven of the 10 morbidity categories resulted in significant costs, with mean $(95 \% \mathrm{Cl})$ additional costs ranging from $\mathrm{f} 7483$ ( $\mathrm{f3}-\mathrm{f17} 289$ ) to $\mathrm{f66} 784$ (£40 609-£103 539) per patient. On average all morbidities combined increased hospital costs by $22.3 \%$. Total burden to the UK health service exceeded $£ 21$ million each year.

Conclusion Postoperative morbidities are associated with a significant financial burden. Our findings could aid clinical teams and hospital providers to account for costs and contextualise quality improvement initiatives.

\section{INTRODUCTION}

Each year more than 5000 paediatric cardiac surgery procedures are performed in the UK. ${ }^{1}$ Advancements in preoperative, perioperative and postoperative care have transformed outcomes, greatly reducing mortality in the immediate postoperative period. ${ }^{2}$ Patients with complex heart defects and pre-existing conditions now routinely survive surgery. ${ }^{3}$ Alternative measures of care quality are needed; postoperative morbidities are considered the next important challenge for clinical teams.

\section{What this study adds?}

- This is the first prospective economic analysis to report the significant costs associated with morbidities for this population at the patient, provider and national levels.

Early postoperative morbidities are defined as adverse effects on health which are linked to a surgical procedure. The Multi-Societal Database Committee for Pediatric and Congenital Heart Disease published a series of articles addressing the impact of postoperative morbidities ${ }^{4-9}$ and the Society of Thoracic Surgery explored complication rates within this database. ${ }^{10}$ This work established that morbidities prolong hospital stay and increase the risk of further complications and death. ${ }^{11}$ Where costs of postoperative morbidities have been reported, they are predominately limited to measuring variations in hospital costs in relation to outcomes. ${ }^{12-14}$ In the UK, work by our group ${ }^{15}$ and a major review of the specialty ${ }^{16}$ calls for outcomes including morbidity, to be monitored in a meaningful way.

Our analysis uses prospective, patient-level cohort data and incidence rates to calculate the impact of morbidities on per-patient costs, hospital costs and annual financial burden for the UK health system.

\section{METHODS}

\section{Study overview}

This study was one element of a 5-year research project to select and define important early morbidities linked to paediatric cardiac surgery and measure their incidence and impact for UK children. ${ }^{17}$ The objective of the economic analysis was to calculate the costs of postoperative morbidities following paediatric cardiac surgery.

Regression modelling of patient-level data from a prospective, case-matched cohort study of 666 children was used to measure hospital resource use in patients with and without morbidities. The 
incidence of morbidities for 3090 consecutive surgical procedures was measured contemporaneously by study centres (incidence data set), facilitating further analysis of costs at the provider level and an extrapolation using national mandatory audit data to estimate the annual financial burden on the UK health service.

\section{Setting}

Patients were recruited from October 2015 to June 2017 in five UK centres (Birmingham Children's Hospital, Bristol Children's Hospital, Evelina London Children's Hospital, Great Ormond Street Hospital for Children NHS Foundation Trust, The Royal Hospital for Sick Children Glasgow). Patients and the public were involved in the wider study but not directly in the economic analysis.

\section{Patients}

The study recruited children from birth to 17 years of age, undergoing open and closed cardiac surgery procedures subject to audit by the National Congenital Heart Disease Audit (NCHDA) (online supplementary appendix 1).

Families with children who met the inclusion criteria were approached to take part in the cohort study unless they were not UK residents, or no family member spoke sufficient English to participate.

The following patients were excluded:

- Premature babies undergoing persistent ductus arteriosus ligation.

- Those undergoing cardiothoracic transplant and tracheal surgeries.

- Those undergoing isolated interventional cardiology procedures.

Each centre attempted to match children with and without morbidities by age, ventricle status (defects of one or both cardiac ventricles) and surgical procedure. ${ }^{17}$

\section{Classification of morbidities}

Predefined morbidities were extracorporeal life support (ECLS), acute neurological event, unplanned reintervention, feeding problems, major adverse event, prolonged pleural effusion, postsurgical infection morbidity, renal support and necrotising enterocolitis. Definitions have been published previously $^{18}$ and are summarised in online supplementary appendix 2 .

Patients were categorised as follows:

- Children without postoperative morbidity.

- Children who experienced a single morbidity (not ECLS).

- Children who experienced more than one morbidity not including ECLS .

- Children who needed postoperative ECLS whether on its own or in combination with other morbidities.

\section{Data collection}

The observation period commenced on the day of the qualifying surgical procedure (day 1) and concluded 6 months later (day 183). Hospital costs were a summation of: operating theatre costs for the initial surgery and any additional procedures; high dependency/intensive care unit (ICU) costs; ward costs and all outpatient visit costs during the observation period. For children who died within the observation period $(n=39)$, data were collected until the date of death.

\section{Resource use}

Operating theatre time (minutes) and number of ward days were extracted from hospital information systems. ICU data were extracted from the Paediatric Intensive Care Audit Network database. Number of outpatient visits was reported by families at follow-up visits $(6,12$ and 26 weeks). Research staff monitored data for accuracy.

\section{Unit costs}

Unit costs were obtained from published sources ${ }^{19-21}$ and inflated (2016/2017 UK£) where necessary. Healthcare resource groups were assigned for each day of ICU stay: intensive care extracorporeal membrane oxygenation (ECMO)/ECLS (cost per day $£ 5440)$; intensive care advanced enhanced (£3748); intensive care advanced (£2538); intensive care basic enhanced (£2151); intensive care basic (£1899); high dependency advanced (£1448); high dependency (£1173); and enhanced care $(£ 870) .{ }^{19}$ The daily ward cost of the study centre closest to the mean value for all centres was used; $£ 904$ for children $<2$ years and $£ 680$ for children $\geq 2$ years. For operating theatres, the cost per minute closest to the mean across centres $(£ 13.39)$ was used. Each outpatient visit was assigned published national average costs for paediatric outpatient visits (£199). ${ }^{19}$

\section{Data analysis}

\section{Handling missing data}

Measures of inpatient resource had 3\%-14\% of missing data. Outpatient attendance was reliant on self-reporting, 19\% of data were missing. Multiple imputation to account for missing data was undertaken using explanatory variables without missing values. $^{22}$ Twenty imputed data sets were generated using an iterative Markov chain Monte Carlo procedure based on multivariate normal regression.

\section{Case mix adjustment}

Confounding variables from the analysis of clinical outcomes which were predefined and validated ${ }^{23}$ were tested using a forward selection and backward elimination technique on imputed data. Variables with a significant ( $p$ value $<0.05$ ) association with costs were: age, weight by age, congenital morbidity, pre-existing severe illness, Down's syndrome, cardiac diagnosis, procedure type, death within 6 months and study centre.

\section{Regression analysis}

We used a generalised linear model with gamma family and $\log$ link, recommended for skewed cost data. ${ }^{24}$ To account for multiple imputation, coefficients and SEs were computed using combination rules. ${ }^{22}$ 'No morbidities' was the reference category. Coefficients with $\mathrm{p}$ values $<0.05$ were considered significantly different from zero. All analyses were performed in Stata v14. ${ }^{25}$

Per-patient costs are expressed as marginal effects illustrating the mean difference in 6-month hospital costs between the morbidity category and omitted category (no morbidity), conditional on the covariates. To compute marginal effects we: (1) exponentiated the coefficient for each morbidity; (2) multiplied this by the mean of the omitted category; and (3) subtracted the mean of the omitted category from this product. ${ }^{26}$

Annual financial burden to the UK health service

The financial burden to the health service is the additional cost resulting from treating morbidities in the UK population each year. We extrapolated our results to the UK population using the following methods: 
I. We calculated the annual incidence rate at each study centre (A-E) for every morbidity category including the no morbidity category (1-11)(eg, [incidence of morbidity category at site $\mathrm{A} / \mathrm{month}$ of observation site $\mathrm{A}] \times 12=\mathrm{A}^{1}, \mathrm{~A}^{2} \ldots$ $\left.\mathrm{A}^{11}\right)$.

II. We summed the rate of each individual category across all study centres $\left(\mathrm{eg}, \mathrm{A}^{1}+\mathrm{B}^{1}+\mathrm{C}^{1}+\mathrm{D}^{1}+\mathrm{E}^{1}=\mathrm{S}^{1}\right)$; the total of which gives the annual number of procedures across all study sites $\left(S^{1}+S^{2} \ldots+S^{11}=S^{T O T}\right)$.

III. We identified the rates of equivalent procedures nationally as reported in UK mandatory audits over the same period (2014-2017) 3 for all National Health Service (NHS) centres in England, Wales and Scotland. In Ireland, all patients are treated at a single centre. To account for Northern Irish patients, $28 \%$ of cases from this centre were included. ${ }^{27}$ The resulting total number of procedures for the UK was averaged over the 3 years $\left(\mathrm{P}^{\mathrm{TOT}}\right)$.

IV. We divided the UK population procedure rate by the study procedure rate $\left(\mathrm{P}^{\mathrm{TOT}} / \mathrm{S}^{\mathrm{TOT}}\right)$ to calculate an extrapolation factor to convert study-specific results to national estimates.

V. We multiplied this extrapolation factor by the incidence of each category to estimate the numbers for the UK population and multiplied this by the cost of each category to calculate the national annual burden of each morbidity to the UK health service.

Costs of morbidities for UK hospital providers

In order to contextualise results for hospital providers we applied the per-patient costs to each of the 10 morbidities and the no morbidity category to the annual incidence reported by the 12 UK centres ${ }^{3}$ and calculated the variation in costs according to activity.

\section{RESULTS}

\section{Study population}

Six hundred and sixty-six children were recruited to the cohort study, the proportion in each category was: no morbidity $n=326$ (48.9\%), prolonged pleural effusion $\mathrm{n}=50$ (7.5\%), feeding problems $n=45(6.7 \%)$, acute neurological event $n=6(0.9 \%)$, necrotising enterocolitis $\mathrm{n}=11(1.6 \%)$, postsurgical infection morbidity $\mathrm{n}=11(1.6 \%)$, unanticipated reintervention $\mathrm{n}=24$ (3.6\%), renal support $n=22(3.3 \%)$, major adverse event $n=26$ (3.9\%), multiple morbidities $n=118(17.7 \%)$ and ECLS $n=27$ $(4.0 \%)$. Characteristics of patients with and without morbidities are shown in table 1 and by morbidity category in online supplementary appendix 3 .

Complete data for 6-month hospital costs (operating theatre costs, high dependency/ICU costs, ward costs and outpatient visits over the 6-month postoperative period) were available for $538(81 \%)$.

\section{Regression analysis}

For children without morbidities, the mean-adjusted 6-month predicted cost per patient was $£ 24143$. Regression modelling identified significant marginal effects (increase from $£ 24$ 143) in seven morbidity categories with mean $(95 \% \mathrm{CI})$ values of: prolonged pleural effusion $£ 7483$ ( $£ 3-£ 17289$ ); renal support $£ 11241$ ( $£ 936-$ $£ 25$ 781); necrotising enterocolitis $£ 16592$ (£599-£42 924); feeding problems $£ 17927$ ( $£ 8057-£ 30$ 824); unplanned reintervention $£ 22903$ ( $£ 9598-£ 41456$ ); multimorbidities $£ 37697$ ( $£ 25971$ -£52 167); and ECLS $£ 66784$ ( $£ 40609-£ 103$ 539) (table 2).

\section{Annual financial burden to the UK health service}

The total calculated cost of 6-month postoperative hospital services for the UK population was $£ 115864753$ ( $£ 103$ $162820-£ 128566$ 686). If no child incurred early postoperative morbidity this cost would be $£ 94785418$ ( $£ 81931327-$ $£ 107639509$ ), resulting in an annual financial burden to the NHS from early postoperative morbidities of $£ 21079335$ (£19 331 430-£22 827 240) (table 3).

\section{Costs of morbidities for hospital service providers}

In the UK, there are 12 hospitals performing paediatric cardiac surgery with annual procedure rates ranging from 226 to $628,{ }^{3}$ the average rate per centre is 367 procedures, per year. Applying per-patient costs, we calculated the cost of 6-month postoperative care for the average hospital to be $£ 9655396$, of which $£ 1$ 756611 was additional cost from morbidities, representing a $22.3 \%$ increase in costs (table 4). For the centre performing the most procedures in the NCHDA, calculated total cost would be $£ 18533638$ with $£ 3371834$ due to morbidities; for the centre performing the fewest procedures, total cost is $£ 6669748$ with a morbidity burden of $£ 1213430$.

\section{DISCUSSION}

\section{Principal findings}

Seven early postoperative morbidities following paediatric cardiac surgery were associated with significant increases in perpatient 6-month hospital costs compared with the same costs for children without morbidity. The magnitude of additional resource use for patients who experience morbidities represents a substantial cost burden for hospital providers, with an average increase in costs for UK centres of $22.3 \%$. When extrapolated to the national patient population, the estimated additional financial burden of early postoperative morbidities for the UK health service exceeds $£ 21$ million each year.

Given these considerable costs, our data support the argument that addressing morbidities should be the next major focus for improving outcomes for patients as in addition to clinical gains, care quality improvements that reduce morbidities could also be highly cost-effective.

\section{Strengths and limitations of this research}

To our knowledge, this is the first study to report the financial impact of clinically important morbidities for this patient population. Our analysis uses rich patient-level measures of resource use collected specifically for the purpose of measuring costs. Measures of hospital resource use had high level of completeness and the sample population is representative of the UK patient population in terms of conditions, procedures, risk factors and outcomes. $^{18}$

The method of cohort assignment which allocated comparable patients to the case and control cohorts is likely to have reduced intersite variability, which is a limitation often seen in observational cohort studies. For children without morbidities, the survival rate at 6 months was $99.3 \%$, and the median length of stay was 8 days, suggesting that the morbidities selected captured the majority of complication-related adverse outcomes for the population. ${ }^{23}$ Monitoring of the incidence of each morbidity category in 3090 consecutive procedures across half of all UK centres over several years facilitated a credible calculation of annual financial burden for the NHS.

The main limitation of our work is that we were only able to illustrate costs for the 6-month period following surgery. The consequences of this fixed observation period are, first, that for 
Table 1 Characteristics of cohort study patients with and without morbidities

\begin{tabular}{|c|c|c|c|c|}
\hline Variable & Category & No morbidity $n=326(\%)$ & Any morbidity $n=340(\%)$ & Total (\%) \\
\hline \multirow[t]{2}{*}{ Sex } & Female & $137(42)$ & $155(47)$ & $292(44)$ \\
\hline & Male & $189(58)$ & $185(53)$ & $374(56)$ \\
\hline \multirow{5}{*}{$\begin{array}{l}\text { Income category } \\
\text { (per year) }\end{array}$} & Up to $f 10000$ & $31(9)$ & $24(7)$ & $55(8)$ \\
\hline & f10 000-f20 000 & $67(21)$ & $87(25)$ & $154(23)$ \\
\hline & f20 001-f50 000 & $118(36)$ & $113(34)$ & $231(35)$ \\
\hline & More than $£ 50000$ & $73(22)$ & $57(16)$ & $130(20)$ \\
\hline & Unknown & $37(12)$ & $59(18)$ & $96(14)$ \\
\hline \multirow[t]{2}{*}{ Survived beyond 6 months } & Yes & $322(99)$ & $305(90)$ & $627(94)$ \\
\hline & No & 4 & 35 & $39(6)$ \\
\hline \multirow[t]{5}{*}{ Hospital centre } & A & $79(24)$ & $106(31)$ & $185(28)$ \\
\hline & B & $69(21)$ & $66(19)$ & $135(20)$ \\
\hline & $\mathrm{C}$ & $78(24)$ & $78(23)$ & $156(23)$ \\
\hline & $\mathrm{D}$ & $68(21)$ & 65 (19) & $133(20)$ \\
\hline & $\mathrm{E}$ & $32(10)$ & $25(4)$ & $57(9)$ \\
\hline \multirow[t]{3}{*}{ Ethnicity } & White & $226(69)$ & $219(64)$ & $445(67)$ \\
\hline & Non-white & $92(28)$ & $99(31)$ & $191(29)$ \\
\hline & Missing & $8(2)$ & $22(6)$ & $30(5)$ \\
\hline \multirow[t]{3}{*}{ Weight for age } & Normal & $212(65)$ & $219(64)$ & $431(65)$ \\
\hline & Low & $90(28)$ & $103(30)$ & $193(29)$ \\
\hline & Missing & $24(7)$ & $18(5)$ & $42(6)$ \\
\hline \multirow[t]{2}{*}{ Premature* } & No & $300(92)$ & $306(90)$ & $606(91)$ \\
\hline & Yes & 26 & 34 & $60(9)$ \\
\hline \multirow[t]{2}{*}{ Congenital comorbidity* } & No & $281(86)$ & $264(78)$ & $545(82)$ \\
\hline & Yes & 45 & 76 & $121(18)$ \\
\hline \multirow[t]{2}{*}{ Pre-existing severity of illness indicators* } & No & $277(85)$ & $265(78)$ & $542(81)$ \\
\hline & Yes & 49 & 75 & $124(19)$ \\
\hline \multirow[t]{2}{*}{ Preacquired comorbidity* } & No & $279(85)$ & $290(85)$ & $569(85)$ \\
\hline & Yes & 47 & 50 & $97(15)$ \\
\hline \multirow[t]{2}{*}{ Down's syndrome* } & No & $299(92)$ & $311(91)$ & $610(92)$ \\
\hline & Yes & 27 & 29 & $56(8)$ \\
\hline \multirow[t]{2}{*}{ Pre-existing additional cardiac risk factort } & No & $301(92)$ & $309(91)$ & $610(92)$ \\
\hline & Yes & 25 & 31 & $56(8)$ \\
\hline \multirow[t]{5}{*}{ Diagnosis category $\dagger$} & A (most complex) & $40(12)$ & $48(14)$ & $88(14)$ \\
\hline & B & $34(10)$ & $56(16)$ & $90(14)$ \\
\hline & $\mathrm{C}$ & $62(19)$ & $62(18)$ & $124(19)$ \\
\hline & $\mathrm{D}$ & $89(27)$ & $107(31)$ & $196(29)$ \\
\hline & E (least complex) & $101(31)$ & $67(20)$ & $168(25)$ \\
\hline \multirow[t]{3}{*}{ Procedure category $\ddagger$} & A: Palliative/staged & 65 (19) & $90(25)$ & $155(23)$ \\
\hline & B: Reparative/corrective & $190(58)$ & $169(50)$ & $359(54)$ \\
\hline & C: Ambiguous & $71(22)$ & $81(24)$ & $152(23)$ \\
\hline \multirow[t]{3}{*}{ Age category } & Neonate & $114(35)$ & $146(43)$ & $260(39)$ \\
\hline & Infant & $130(40)$ & $120(35)$ & $250(38)$ \\
\hline & Child & $82(25)$ & $74(22)$ & $156(23)$ \\
\hline
\end{tabular}

*Comorbidities are: preacquired comorbidity; congenital comorbidity excluding Down's syndrome; Down's syndrome, additional cardiac risk factors (eg, cardiomyopathy); prematurity; severity of illness indicator.

†Cardiac diagnosis category based on the Partial Risk Adjustment in Surgery (PRAiS2) ranking order and further aggregated by an expert panel, group A the most complex and group E the least (online supplementary appendix 4).

$\ddagger$ Specific procedure category based on National Congenital Heart Disease Audit (NCHDA) algorithm, reparative or corrective operation; palliative or staging operation; ungrouped operation (could not be determined). ${ }^{18}$

children with the most complex recoveries clinical and cost impacts can extend well beyond this time point, and, second, the variation in length of stay within the 6-month period directly impacted the admissible data collection period for other types of resource use. For our sample population, 95\% of children without morbidity had been discharged from the hospital before 6 weeks, therefore, costs of readmissions and outpatient appointments were measured for 18 weeks, whereas $30 \%$ of children with multiple morbidities and $48 \%$ of those who had ECLS remained in hospital beyond 6 weeks and so those same costs were measured over a shorter period. To account for this, we have been careful to stipulate that our results are representative of the actual costs incurred in the 6 months following surgery. Nevertheless, since the patients with morbidities and a greater length of stay would also have been very likely to require more intense follow-up in the out-of-hospital phase, extending beyond our 6-month window, their true overall 


\begin{tabular}{|c|c|c|c|}
\hline Morbidity category & Coefficient & $P$ value & Marginal effect $(95 \% \mathrm{Cl})$ \\
\hline Extracorporeal life support & 1.326 & $<0.001$ & $f 66784$ (£40 609 to $£ 103539$ ) \\
\hline $\begin{array}{l}\text { Multiple morbidity (except } \\
\text { ECLS) }\end{array}$ & 0.941 & $<0.001$ & f37 697 (£25 971 to $£ 52$ 167) \\
\hline Unplanned reoperation & 0.667 & $<0.001$ & f22 903 ( $£ 9598$ to $£ 41456$ ) \\
\hline Feeding problems & 0.555 & $<0.001$ & f17 927 (£8057 to f30 824) \\
\hline Necrotising enterocolitis & 0.523 & 0.04 & f16 592 (£599 to $f 42$ 924) \\
\hline Acute neurological event & 0.458 & 0.21 & f14 042 (-f5424 to f53 753) \\
\hline Renal support & 0.382 & 0.03 & f11 241 ( $\mathrm{f936}$ to $f 25$ 781) \\
\hline $\begin{array}{l}\text { Postsurgical infection } \\
\text { morbidity }\end{array}$ & 0.347 & 0.17 & $\mathrm{f} 10025$ (-f3266 to $£ 31$ 779) \\
\hline Prolonged pleural effusion & 0.270 & 0.05 & f7483 ( $£ 3$ to $£ 17289$ ) \\
\hline Major adverse event & 0.189 & 0.32 & $f 5030(-£ 4119$ to $f 18359)$ \\
\hline \multicolumn{4}{|c|}{ Observations from imputed data, $n=666$} \\
\hline \multicolumn{4}{|c|}{$\begin{array}{l}\text { In every case the regression model was a generalised linear model with gamma family and log link. } \\
\text { The marginal effects are the change in costs versus the omitted category (no morbidities). Data include } \\
\text { values imputed using multiple imputation. Costs are in } 2016 / 2017 \text { UKf. Controls were also included } \\
\text { in every model for: age; weight by age; whether or not the patient had a pre-existing congenital } \\
\text { morbidity, pre-existing severe illness or Down's syndrome; underlying diagnosis prompting cardiac } \\
\text { surgery; type of cardiac procedure performed; whether or not the patient died within } 6 \text { months; and } \\
\text { sudy centre. } \\
\text { ECLS, extracorporeal life support. }\end{array}$} \\
\hline
\end{tabular}

costs would have been even higher than presented here. Further research needs to be undertaken to understand the possible cost impact of those morbidities which did not significantly increase costs as the numbers in these groups were small and it is likely that the sample was underpowered.

Non-hospital costs and costs borne by families were recorded in this study, however, the variation in follow-up and the significant level of missing data meant we were unable to report them. Despite the challenges of collecting data these costs warrant further research and accurate reporting.

\section{Implications for clinical practice and policy}

Benchmarking and public reporting of outcomes are methods of comparative assessment used worldwide to drive quality
Table 4 Costs of morbidities to hospital providers

\begin{tabular}{|c|c|c|c|}
\hline & $\begin{array}{l}\text { Annual incidence of } \\
\text { morbidity averaged } \\
\text { across } 12 \text { NCHDA } \\
\text { centres }\end{array}$ & $\begin{array}{l}\text { Average annual } \\
\text { marginal cost per } \\
\text { provider }\end{array}$ & $\begin{array}{l}\text { Average annual } \\
\text { total cost per } \\
\text { provider }\end{array}$ \\
\hline Morbidity type & $\begin{array}{l}\text { Table } 3, \\
\text { column D/12 }\end{array}$ & $\begin{array}{l}\text { Table 3, } \\
\text { column E/12 }\end{array}$ & $\begin{array}{l}\text { Table 3, column } \\
\text { F/12 }\end{array}$ \\
\hline No morbidity & 255.5 & - & f6 168537 \\
\hline Acute neurological event & 1.5 & f0 & f36 215 \\
\hline Unplanned reoperation & 6.3 & f143144 & f294038 \\
\hline Feeding problems & 10.3 & £185 246 & $£ 434723$ \\
\hline Renal support & 4.2 & f46 838 & f147 433 \\
\hline Major adverse event & 3.7 & f0 & f88 524 \\
\hline Extracorporeal life support & 6.8 & $£ 450792$ & f613 757 \\
\hline Necrotising enterocolitis & 3.4 & f56 689 & f139 178 \\
\hline $\begin{array}{l}\text { Postsurgical infection } \\
\text { morbidity }\end{array}$ & 2.9 & f0 & f70 417 \\
\hline Prolonged pleural effusion & 11.8 & f88 549 & f374 241 \\
\hline Multiple morbidity & 20.8 & f785 354 & f1 288333 \\
\hline Total & 327.2 & f1 756611 & f9 655396 \\
\hline
\end{tabular}

NCHDA, National Congenital Heart Disease Audit.

improvements. $^{28} 29$ The NCHDA has reported centre-specific, risk-adjusted mortality rates following paediatric cardiac surgery since 2005 , however a consistent 30 -day postoperative mortality rate of $2 \%$ has prompted clinical teams to look for alternate care quality indicators. A rapid literature review in 2017 by the Canadian Institute of Health Economics included two studies reporting statistically significant reductions in morbidities as a result of external benchmarking. ${ }^{30}$ In terms of our results, a crude overall reduction of 5\% in yearly incidence of morbidities with significant impacts on 6-month hospital costs equates to an annual cost saving for the NHS of $£ 1053966$. With mandatory auditing well established in the UK it is conceivable that expanding public reporting and benchmarking to include clinically important morbidities could be a cost-effective quality improvement initiative.

Table 3 Annual financial burden to the UK health service

\begin{tabular}{|c|c|c|c|c|c|c|}
\hline Morbidity type & $\begin{array}{l}\text { Marginal effect on costs } \\
\text { of morbidity (increase } \\
\text { from } f 24 \text { 143) }\end{array}$ & $\begin{array}{l}\text { Total per-patient } \\
\text { cost (cost of no } \\
\text { morbidity+marginal } \\
\text { effect) }\end{array}$ & $\begin{array}{l}\text { Annual morbidity } \\
\text { incidence-study } \\
\text { centres* }\end{array}$ & $\begin{array}{l}\text { Annual morbidity } \\
\text { incidence- } \\
\text { extrapolated to UK } \\
\text { population }\end{array}$ & $\begin{array}{l}\text { Annual cost to health } \\
\text { service of morbidity }\end{array}$ & $\begin{array}{l}\text { Annual national } \\
\text { total cost }\end{array}$ \\
\hline & A & $B(A \times J)$ & C & $D(C x J)$ & $E(A \times D)$ & $F(B \times D)$ \\
\hline No morbidity & - & f24 143 & 1415.1 & 3066 & - & f74 022438 \\
\hline Acute neurological event & f0 & f24 143 & 8.3 & 18 & $£ 0$ & £434 574 \\
\hline Unplanned reoperation & f22 903 & f47 046 & 34.7 & 75 & f1 717725 & f3 528450 \\
\hline Feeding problems & f17 927 & f42 070 & 57.2 & 124 & f2 222948 & f5 216680 \\
\hline Renal support & f11 241 & f35 384 & 23.3 & 50 & f562 050 & f1 769200 \\
\hline Major adverse event & f0 & f24 143 & 20.4 & 44 & f0 & f1 062292 \\
\hline Extracorporeal life support & f66 784 & £90 927 & 37.5 & 81 & f5 409504 & £7 365087 \\
\hline Necrotising enterocolitis & f16 592 & f40 735 & 19.1 & 41 & f680 272 & f1 670135 \\
\hline Postsurgical infection morbidity & $\mathrm{f0}$ & f24 143 & 16.0 & 35 & £0 & £845005 \\
\hline Prolonged pleural effusion & f7483 & f31 626 & 65.4 & 142 & f1 062586 & f4 490892 \\
\hline Multiple morbidity & f37 697 & f61 840 & 115.4 & 250 & f9 424250 & f15 460000 \\
\hline Total & & & 1812.4 & 3927 & f21 079335 & f115 864753 \\
\hline $\begin{array}{l}\text { Total incidence } \\
\text { NCHDA reports } \\
\text { 2014-2017t }\end{array}$ & $\begin{array}{l}\text { Annualtotal morbidity } \\
\text { incidence—study centres }\end{array}$ & Extrapolation factor & $\begin{array}{l}\text { Annual total morbidity } \\
\text { cost for UK patient } \\
\text { population }\end{array}$ & $\begin{array}{l}\text { Annual national total } \\
\text { cost }\end{array}$ & $\begin{array}{l}\text { Annual national cost } \\
\text { with no morbidities }\end{array}$ & $\begin{array}{l}\% \text { increase in } \\
\text { cost }\end{array}$ \\
\hline$H(G / 3)$ & I & $\mathrm{J}(\mathrm{H} / \mathrm{I})$ & $\mathrm{K}$ & L & $M(K-L)$ & $N([K / M] \times 100)$ \\
\hline 11782 & 1812.4 & 2.167 & f21 079335 & f115 864753 & f94 785418 & $22.3 \%$ \\
\hline
\end{tabular}

*Calculated from observed incidence rates of 3090 consecutive surgical procedures across all study centres.

†Calculated from reported rates of equivalent procedures in mandatory audit report from NCHDA rounded in this table to one decimal place.

NCHDA, National Congenital Heart Disease Audit. 


\section{Unanswered questions and future research}

Paediatric cardiac surgery is a highly invasive, traumatic life event for children and their families and there is a need to advance the reporting of costs beyond morbidity and relate them to patients' postoperative functional status and quality of life.

Finally, the methodology we have used, including the use of costing and outcome data from a number of sources populated as a result of existing reporting, costing and benchmarking initiatives, which are not in principle specific to paediatric cardiac surgery, provides a template that could be adapted more broadly within the NHS to elicit similar insights into other areas where the cost of hospitalisation is analogous to outcomes of interest.

\section{CONCLUSION}

Costs associated with postoperative morbidity following paediatric cardiac surgery are substantial. Our research identifies the financial impact of early postoperative morbidities on hospital providers of paediatric surgery and the UK NHS. As mortality rates improve and increasingly complex patients survive their surgery, the cost of postoperative care is likely to rise. Data from our analysis could aid clinical teams and hospital providers to account for these costs and contextualise potential care quality improvement initiatives.

\section{Author affiliations}

'Department of Public Health and Primary Care, University of Cambridge, Cambridge, UK

${ }^{2}$ Cardiorespiratory Division, Great Ormond Street Hospital for Children NHS

Foundation Trust, London, UK

${ }^{3}$ Clinical Operational Research Unit, University College of London, London, UK

${ }^{4}$ Paediatric Intensive Care Unit, Great Ormond Street Hospital NHS Foundation Trust, London, UK

${ }^{5}$ Department of Cardiac Surgery, Birmingham Women's and Children's NHS

Foundation Trust, Birmingham, UK

${ }^{6}$ Paediatric Intensive care Unit, NHS Greater Glasgow and Clyde Inverclyde Royal Hospital, Glasgow, UK

${ }^{7}$ Department of Cardiac Surgery, University Hospitals Bristol NHS Foundation Trust, Bristol, UK

${ }^{8}$ Department of Paediatric Intensive Care, Evelina Children's Hospital, Guy's and St Thomas' NHS Foundation Trust, London, UK

${ }^{9}$ Paediatric Epidemiology Biostatistics, Institute of Child Health, London, UK

\section{Twitter Christina Pagel @chrischirp}

Acknowledgements We are very grateful to all the families who participated in the study. By way of thanks we recognise the contributions of: Martin Utley, Sheryl Snowball, Luke Maidment, Sarah Bohannon, Liz Smith, Kate Penny-Thomas, Joanne Webb, Sinead Cummins, John Stickley, Natasha Khan, Teresa Dickson, Ray Samson, Isobel Mcleod, Paul Wellman, Rhian Lakhani, Kathleen Selway, Carrie Cherrington, Andrew Parry, Rob Tulloh, Bill Gaynor, Rodney Franklin, Lisa Allera, Kate Bull, Trevor Ritchens, Branko Mimic, Jon Smith, Lyvonne Tume, Vibeke Hjortdal, Michael Vath, Tom Treasure, Anne Keatley Clarke and Bea Tuten.

Funding This project was funded by the National Institute for Health Research Health Services and Delivery Research programme (Project No 12/5005/06). KB, DR, JW and VT were supported by the National Institute for Health Research Biomedical Research Centre at Great Ormond Street Hospital for Children NHS Foundation Trust and University College London.

Disclaimer The views and opinions expressed therein are those of the authors and do not necessarily reflect those of the NIHR HS\&DR programme or the Department of Health and Social Care.

Competing interests None declared.

Patient consent for publication Not required.

Ethics approval The study has ethical approval from London City Road Research Ethics Committee (14-L0-1442).

Provenance and peer review Not commissioned; externally peer reviewed.

Data availability statement Data are not publicly available. For data to be made available to a third party, specific ethical and HRA approvals would be required.
Open access This is an open access article distributed in accordance with the Creative Commons Attribution Non Commercial (CC BY-NC 4.0) license, which permits others to distribute, remix, adapt, build upon this work non-commercially, and license their derivative works on different terms, provided the original work is properly cited, appropriate credit is given, any changes made indicated, and the use is non-commercial. See: http://creativecommons.org/licenses/by-nc/4.0/.

\section{ORCID iDs}

Emma Hudson http://orcid.org/0000-0002-0505-5049

Christina Pagel http://orcid.org/0000-0002-2857-1628

Shane M Tibby http://orcid.org/0000-0001-7774-8656

\section{REFERENCES}

1 NHS England. Paediatric congenital heart disease specification. Available: www. england.nhs.uk

2 Brown KL, Crowe S, Franklin R, et al. Trends in 30-day mortality rate and case mix for paediatric cardiac surgery in the UK between 2000 and 2010. Open Heart 2015;2:000157.

3 National congenital heart disease audit 2014-2017 summary report. Available: https://www.nicor.org.uk/wp-content/uploads/2018/11/National-Congenital-HeartDisease-Audit-Summary-Report-2014-17.pdf

4 Bacha EA, Cooper D, Thiagarajan R, et al. Cardiac complications associated with the treatment of patients with congenital cardiac disease: consensus definitions from the Multi-Societal database Committee for pediatric and congenital heart disease. Cardiol Young 2008; 18 (Suppl 2):196-201.

5 Bird GL, Jeffries HE, Licht DJ, et al. Neurological complications associated with the treatment of patients with congenital cardiac disease: consensus definitions from the Multi-Societal database Committee for pediatric and congenital heart disease. Cardiol Young 2008; 18 (Suppl 2):234-9.

6 Deal BJ, Mavroudis C, Jacobs JP, et al. Arrhythmic complications associated with the treatment of patients with congenital cardiac disease: consensus definitions from the Multi-Societal database Committee for pediatric and congenital heart disease. Cardiol Young 2008;18 (Suppl 2):202-5.

7 Dickerson H, Cooper DS, Checchia PA, et al. Endocrinal complications associated with the treatment of patients with congenital cardiac disease: consensus definitions from the Multi-Societal database Committee for pediatric and congenital heart disease. Cardiol Young 2008;18 (Suppl 2):256-64.

8 Ghanayem NS, Dearani JA, Welke KF, et al. Gastrointestinal complications associated with the treatment of patients with congenital cardiac disease: consensus definitions from the Multi-Societal database Committee for pediatric and congenital heart disease. Cardiol Young 2008;18 (Suppl 2):240-4.

9 Cooper DS, Jacobs JP, Chai PJ, et al. Pulmonary complications associated with the treatment of patients with congenital cardiac disease: consensus definitions from the Multi-Societal database Committee for pediatric and congenital heart disease. Cardiol Young 2008;18 (Suppl 2):215-21.

10 Jacobs ML, O'Brien SM, Jacobs JP, et al. An empirically based tool for analyzing morbidity associated with operations for congenital heart disease. J Thorac Cardiovasc Surg 2013;145:1046-57.

11 Brown KL, Ridout DA, Goldman AP, et al. Risk factors for long intensive care unit stay after cardiopulmonary bypass in children. Crit Care Med 2003;31:28-33.

12 Romley JA, Chen AY, Goldman DP, et al. Hospital costs and inpatient mortality among children undergoing surgery for congenital heart disease. Health Serv Res 2014;49:588-608.

13 Pasquali SK, Jacobs ML, He X, et al. Variation in congenital heart surgery costs across hospitals. Pediatrics 2014;133:e553-60.

14 Pasquali SK, Gaies MG, Jacobs JP, et al. Centre variation in cost and outcomes for congenital heart surgery. Cardiol Young 2012;22:796-9.

15 Crowe S, Brown KL, Pagel C, et al. Development of a diagnosis- and procedure-based risk model for 30-day outcome after pediatric cardiac surgery. J Thorac Cardiovasc Surg 2013;145:1270-8.

16 NHS. Safe and Sustainable: Childrens' Congenital Cardiac Services, 2011. Available: http://www.chfed.org.uk/wp-content/uploads/2012/06/Safe_and_Sustainable_ Review_of_Childrens_Congenital_Cardiac_Services_in_England_Pre_Consultation_ Business_Case.pdf

17 National Institute for Health Research. Selection, definition and evaluation of important early morbidities associated with paediatric cardiac surgery. Available: https://www.journalslibrary.nihr.ac.uk/programmes/hsdr/12500506/\#/

18 Brown KL, Pagel C, Brimmell R, et al. Definition of important early morbidities related to paediatric cardiac surgery. Cardiol Young 2017;27:747-56.

19 NHS Improvement. Reference costs. Available: https://improvement.nhs.uk/resources/ reference-costs/ [Accessed 19 Jul 2019].

20 Curtis L, Burns A. Unit costs of health and social care 2016, personal social services research unit, University of Kent, Canterbury unit costs of health and social care 2016, 2016. Available: https://www.pssru.ac.uk/project-pages/unit-costs/unit-costs-2016/ [Accessed 19 Jul 2019].

21 NHS Employers. Unit costs of health and social care, 2017. Available: http://www. nhsemployers.org/your-workforce/pay-and-reward/pay/job-evaluation/national-jobprofiles 


\section{Original research}

22 Rubin DB. Multiple imputation for nonresponse in surveys. John Wiley \& Sons, 1987.

23 Brown KL, Pagel C, Ridout D, et al. What are the important morbidities associated with paediatric cardiac surgery? A mixed methods study. BMJ Open 2019;9:e028533.

24 Barber J, Thompson S. Multiple regression of cost data: use of generalised linear models. J Health Serv Res Policy 2004;9:197-204.

25 StataCorp. Stata statistical software: release 14. College Station, TX: StataCorp LP, 2015.

$26 r$ - How to interpret parameters in GLM with family=Gamma - Cross Validated. Available: https://stats.stackexchange.com/questions/96972/how-to-interpretparameters-in-glm-with-family-gamma [Accessed 19 Jul 2019].
27 Population estimates for the UK, England and Wales, Scotland and Northern Ireland - Office for National Statistics. Available: https://www.ons.gov.uk/peoplepopulation andcommunity/populationandmigration/populationestimates/bulletins/annualmidyea rpopulationestimates/mid2018 [Accessed 19 Jul 2019].

28 Behrendt K, Groene 0. Mechanisms and effects of public reporting of surgeon outcomes: a systematic review of the literature. Health Policy 2016;120:1151-61.

29 Ellis J. All inclusive benchmarking. J Nurs Manag 2006;14:377-83.

30 Craig R, Moga C, Guo B, et al. The impacts of public reporting and external benchmarking in cardiac care: a rapid update of the literature. Edmonton, $A B$ : Institute of Health Economics, 2017. 